\title{
Preliminary Study in the Reform of Mechanical Drawing and CAD Teaching
}

\author{
LuQian Duan ${ }^{1}$, XueGuo $\mathrm{An}^{2}$ \\ ${ }^{1}$ Department of Mechanical Engineering, Academy of Armored Forces Engineering, Beijing \\ 100072, China
}

${ }^{2}$ Foreign Training Department, Academy of Armored Forces Engineering, Beijing 100072, China

Email: mary.duan@aliyun.com

Key words: Foreign training; Mechanical Drawing and CAD; Reform in the teaching Abstract: To improve the training quality of foreign military personnel, the reform of "Mechanical Drawing and CAD" teaching is put in practice based on the new Talent Training Program. The result shows that the reform with the characteristic of foreign training is effective in improving foreign training quality.

\section{Introduction}

A primary study of reform on the course "Mechanical Drawing and CAD" is undergone based on the new Talent Training Program and the course standard to improve the training quality of foreign military personnel and teaching effect.

The course "Mechanical Drawing and CAD" is a vocational elementary course among the foreign training core courses and a compulsory course for the engineering oriented specialties. It is also an integrated course combining the two courses "Machine Drawing" and "Mechanical CAD". The aim to offer this course is to cultivate the abilities of foreign military personnel in reading mechanical drawings, space imagination and drawing by $\mathrm{CAD}$, to build the establish in mind the ideas of innovation, engineering and 3D design, to improve the engineering application ability in analyzing and solving the practical problems with engineering thinking, and to lay theoretical and technological base for further study of the following specialized courses.

Some problems have been exposed in the teaching of courses "Mechanical Drawing" and "Mechanical CAD" in the last three years of teaching. If not solved timely, they will hinder finally the improvement of teaching quality.

\section{Exposed Problems}

Contents in Textbook Mismatching Teaching Demands. Being originated from the two courses "Machine Drawing" and "Mechanical CAD", the integrated course "Mechanical Drawing and Mechanical CAD" still uses the original textbooks. However, the old teaching material is found to mismatch with new teaching demands in teaching. As for the mechanical drawing, the drawing standards adapted in original teaching material is out of date and the emphasis of the old teaching material is not up to the new Curriculum Standards and talent training program. With regard to mechanical CAD, the original teaching material is very much behind the times in contents and little in amount of information, losing the action in teaching.

Teaching Mode Mismatching Teaching Demands. The course "Mechanical Drawing and Mechanical CAD" includes two parts: machine drawing and mechanical CAD. The time allotment is $50 \%$ for each part. The sequence is usually the machine drawing first while the 
mechanical CAD second. This kind of arrangement results in the feeling of boring when students learn the theory and the disconnection between the theory and practice when they operate computers for practice. Furthermore, for the limitation of conditions and management, the arrangement of foreign training curricula is like in series, that is, one course is linked with another one in series, and two courses are never opened at the same time. Such a large amount of time in learning and memorizing the dull theory day after day plunge some of the students, especially those who have never learned it before, into a hard situation, no sooner learned than forgotten. As a result, it becomes difficult to use theory guiding practice in practical teaching.

Curriculum Content Mismatching the Demand of Hour-Reduced and Efficiency Improved. The time for the course "Mechanical Drawing and Mechanical CAD" is 78 periods while that of the courses "Machine Drawing" and "Mechanical CAD" is 84 periods in total, showing the decrease in time but the rise in teaching content if the teaching contents are kept unchanged.

Educational Background of Students Mismatching Teaching in Accordance with the Syllabus. In recent years, the number of foreign military personnel to our academy has been increasing each year and the training scale has been enlarged. The demand for high training quality is rising at the same time. However, it is difficult to implement the teaching plan successfully because of the diversity of nations and difference of students in educational background, especially in the use of computer, commanding of English and understanding of fundamental theories. Some of them can operate computer skillfully and grasp the ABC of the software in a short time. But some lack the experience in the use of computer; some even never contact it before. So it is not easy for them to keep up with others at a higher level in operating computers when studying the contents of mechanical CAD. Even though English is expected to be working language in class, the current situation is the English level of some students is still far from normal communication, bringing about the difficulty in understanding and being understood in class. It is not surprising that if you see some students looking up in the dictionary as listening to class. Besides, the difference in educational level, for example, some are college graduates and some even have got the master's degree, result in teaching pace for some students is too fast enough to keep up with.

\section{Reform in Teaching}

As mentioned above, the reform exploration in the course "Mechanical Drawing and CAD" is put in practice. Firstly, a curricula system with foreign training characteristics is constructed, stressing the close integration of engineering practice and concerned equipment. Secondly, a new teaching mode is explored to solve the problems existing in teaching and learning. Finally, new curriculum standards are established and an appropriate textbook is compiled. The active measures in the reform of the course have witnessed the great rise in training quality.

Construct a New Teaching System. According to the new Talent Training Program, new curricular standards are recompiled with the change of study period, training objectives and training requirements, and teaching content. When recompiling the standards, we have thoroughly considered the difference of post-oriented demands, training objects, the reduction of training time, the change of teaching emphases, as well as the difference of teaching contents and the reform of teaching mode.

The course "Mechanical Drawing and CAD" is combined by two courses, but it is not a simple addition of the original contents. Stress will be put on the basic theory, reading of drawing and expressing methods of drawing when teaching the mechanical drawing, among which, "reading" is the emphasis. Emphasis will be placed on the various modeling methods while 
teaching the mechanical CAD, among which, "drawing" is the key. Thus the reading and the drawing are organically integrated. Modern technology is integrated in the traditional teaching mode, not only cultivating the learning ability, but also establishing the consciousness of innovation at the same time.

Meanwhile, the course "Mechanical Drawing and CAD" is one core curriculum for two specialties, the Chassis and Engine Engineering and the Wheel Armored Vehicle Engineering. So the engineering examples must be introduced into the teaching contents. In addition, the learning of reading, the exercise and the 3D modeling must be closely related to the armament and lay a solid foundation for following specialized courses.

Compile a Textbook Suitable for Teaching Demands. A new textbook is recompiled in accordance with the new curriculum standards and the features of foreign students. It is suitable for the teaching demands and avoids the shortcomings of the original book. As for the part of mechanical drawing, the new textbook adopts the latest Chinese National Standards, emphasizes the training on reading drawing, adjusts the number and type of the exercises, increases the engineering example and practice, and stresses the basic knowledge. About the part of mechanical $\mathrm{CAD}$, the new textbook uses more examples related to mechanical equipment, and enumerates in detail the solution steps to let students learn more easily. At the same time, the new textbook adds a large amount of exercises from easy to difficult, helping students consolidate what they have learned. These exercises have integrated the knowledge of the mechanical drawing with that of the mechanical CAD, realizing the theory guiding practice and their unification.

Innovate the Examination Mode. The aim to offer the course "Mechanical Drawing and CAD" is to provide the students with the abilities in reading the mechanical drawing and in 3D modeling. Two examination modes are used: written and computer-based, and the former for the part of mechanical drawing, while the latter for the part of mechanical CAD. But in practice, the students good at reading mechanical drawing sometimes become slow in drawing with rulers. The final score cannot reflect the real and actual level of the students in learning. Additionally, two examinations increase the burden of the students.

So, it is necessary to change the current examination mode. Only computer-based test is adopted, and the final score is comprehensively evaluated considering classroom behavior. However, the examination questions are given in the forms of three views and detail drawing, including three degrees of difficulty: easy, moderate and difficult. As a result, students will not be able to complete the 3D modeling unless they understand the meaning of the given drawing. It does not only examine the ability of reading drawing but also the ability of 3D modeling. The examination results basically reflect learning condition of students.

\section{Improve Teaching Mode}

Carry out Theoretical Teaching and Practical Teaching Alternately.The teaching mode is reformed from the change of the arrangement of contents: from the past sequential pattern to current alternate one. It can avoid the dullness appeared in theoretical teaching and ensure a clear target in practical teaching. As a result, the teaching effects are improved greatly.

Apply Various Teaching Methods. The course "Machine Drawing and Mechanical CAD" includes two parts: the mechanical drawing and mechanical CAD. The former puts emphasis on the classroom teaching, while the latter on the practice. The former is the foundation of the latter. So various teaching methods, such as the Heuristic Teaching, the Interactive Teaching and Inquiry-Based Teaching, are brought into the classroom in accordance with specific contents. Individualized education is advocated. The explanation and interpretation by the teacher are mostly relied on when learning the difficult and abstract chapter or section or point. But for the 
easy points, independent learning by students may be used. Anyway, every student is active to participate in the teaching activities and their interests and enthusiasm are motivated largely, achieving the aim of improving the classroom teaching efficiency.

Compile and Make Teaching Plan and Multimedia Courseware with the Foreign Training Characteristics. English-version multimedia courseware with excellent pictures and texts are compiled on the basis of the curriculum standards and textbook. The courseware fully presents the basic requirements of the curriculum standards and helps students have a good grasp of the essentials and main ideas of curriculum system, and guide students in study and review and obtain a better learning outcome.

When compiling teaching plan, we considered thoroughly about the features of foreign teaching and the difference of students so that we can teach what we have assisted and students can learn what we have taught. That is, each student, whatever his education background is, can get completely what is taught in the classroom.

\section{Teaching Effects}

Evaluation by Students. In the process of learning, all the students considered that it is reasonable in teaching content, proper in teaching means, high in professional quality and responsibility. Most of them found they had achieved a lot in both theoretical knowledge and practical skills after learning the course. One student from Laos said he felt a little difficult to understand the teacher at the beginning as his English was not so good. But with time going on and application of diverse teaching means, he made one progress after another and finally passed the exam by a satisfied score. One student from Zimbabwe said that he seldom used computer in his own country and was slow in understanding the contents of mechanical CAD than others. But with the guidance of the teacher and his efforts after class, he was surprised with what he had learned in this course.

Score Analysis. We analyze the examination result after adopting new examination mode. It coincides with the student learning condition at ordinary times and is ideal relatively, which shows the students master better the basic theory and methods of the course and we achieve the teaching aim.

\section{Conclusions}

To improve the training quality of foreign military personnel, the reform of "Mechanical Drawing and CAD" teaching is put in practice based on the new Talent Training Program. Aiming at some problems met in the process of teaching and learning it, some methods with the characteristic of foreign training have been explored form constructing new teaching system to improving teaching mode and implemented in practice. The results show that these methods are effective.

However, with the increasing enlargement in the training scale, the reform pace of the course can stop to adapt the rising training requirements.

\section{References}

[1] Cheng Guangli,Cai Zhiming, Yin Jingxiang. Application of Seminar Teaching Method to Foreigner-Training in Military Academy[J].Journal of Higher Education Research, 2010,33(3):78-80

[2] Yao Kai, Wu Xueyan. Practical Exploration on Applying Hierarchy Method to Organize Foreign Teaching[J]. China Power Education , 2013 , 263 ( 3 ): 141 - 142. 